\title{
Direct Stator Flux Vector Control Strategy for IPMSM using a Full- order State Observer
}

\author{
Qingwei Yuan*, Zhiyong Zeng* and Rongxiang Zhao ${ }^{\dagger}$
}

\begin{abstract}
A direct stator flux vector control scheme in discrete-time domain is proposed in this paper for the interior permanent magnet synchronous motor (IPMSM) drive to remove the proportional-integral (PI) controller from the direct torque control (DTC) scheme applied to IPMSM and to obtain faster dynamic response and lower torque ripple output. The output of speed outer loop is used as the desired torque angle instead of the desired torque in the proposed scheme. The desired stator flux vector in $d q$ coordinate is calculated with a given amplitude. The state-space equations in discrete-time for IPMSM are established, the actual stator flux vector is estimated in deadbeat manner by a full-order state observer, and then the closed-loop control is achieved by the pole placement. The stator flux error vector is utilized to calculate the reference stator voltage vector. Extracting the angle position and amplitude from the estimated stator flux vector and estimating the output torque are eliminated for the direct feedback control of the stator flux vector. The proposed scheme is comparatively investigated with a PI-SVM DTC scheme by experiment results. Experimental results show the feasibility and advantages of the proposed control scheme.
\end{abstract}

Keywords: Direct stator flux vector control, Direct torque control, Full-order state observer, Interior Permanent Magnet Synchronous Motor (IPMSM)

\section{Introduction}

The permanent magnet synchronous motors (PMSMs) have found an increasingly wide utilization in many industrial applications for their high efficiency, high torqueto-current ratio, simple mechanical construction, easy maintenance, and so forth [1-2]. Among the various control strategies applied to PMSM, field-oriented control (FOC) and direct torque control (DTC) are the two most popular methods for high performance motor drive. Compared with FOC, the DTC scheme has higher dynamic response and a simpler control structure, due to lack of the inner current loop, rotary coordinate transformation blocks and space vector modulation (SVM) block [3]. After the DTC scheme was introduced by Takahashi and Depenbrock to the induction motor drive in the 1980s [4-5], it has been extended to other types of alternating-current (AC) motor drive [6-11]. In [12] and [13], a typical DTC scheme for interior PMSM (IPMSM) drive is presented, where the voltage vector is selected from a switching table with the knowledge of the angular position of the stator flux vector and the outputs of the torque and stator flux hysteresis controllers.

However, due to the utilization of the switching table and hysteresis controllers, disadvantages such as large torque and current ripples, and variable switching

$\uparrow \quad$ Corresponding Author: College of Electrical Engineering, Zhejiang University, China. (rongxiang@zju.edu.cn)

* College of Electrical Engineering, Zhejiang University, China.

Received: May 19, 2016; Accepted: August 13, 2016 frequency, are presented in the motor outputs. To overcome these drawbacks, researchers have paid much attention to this area, and many modified control strategies have been proposed.

Since the switching table is provided with a limited number of voltage vectors, a discrete SVM is proposed in $[14,15]$ and a multilevel inverter and a matrix inverter are adopted in [16-19] respectively, to get more voltage vectors However, with the increase of available voltage vectors, a more complex switching table needs to be defined. In addition, the torque ripple reduction is still unsatisfactory.

Considering that it is not necessary for the active voltage vector to be applied for the whole sampling period, the predictive torque control strategy is introduced. For the predictive control strategy, the duty ratio of the voltage vector selected is determined by the cost functions, such as the torque-ripple minimized control [20], the deadbeat torque control [21,22], and the mean torque control [23]. However, the predictive torque control algorithm is highly dependent on the models of the load and converter, which becomes extremely complex when applied to the IPMSM [24].

When the switching table in the DTC strategies is replaced by the SVM module, sufficient voltage vectors are provided to compensate the errors of the torque and stator flux. Then, the control system design mainly focuses on the algorithms to get the desired stator voltage vector, and various algorithms are proposed by the researchers. A proportional-integral (PI) controller is employed in [6, 25], and a variable structure controller is adopted in [26], to 
calculate the desired voltage vector. Both schemes need plenty of calculation and regulation to achieve a good control performance. A variant of the predictive torque control is proposed in [27]. Although lower torque ripple output is exhibited, the algorithm is more complex when applied to the IPMSM. Two weight factors are employed in [28] to determine the amplitude and angle of the desired voltage vector. It is a time-consumption job to find the proper weight factors.

As the feedback variables, the stator flux plays an important role in the system control. Since the stator flux cannot be directly measured, it is necessary to create an observer to observe the stator flux accurately. The pure integrator used in the traditional voltage-based model deteriorates the performance of the estimator due to the DC drift and initial value [29]. A low-pass-filter estimator with compensation of amplitude and phase angle is utilized in [28] to remedy the problems. To reduce the parameter sensitivity, many closed-loop adaptive observers based on advance models have been developed, such as an adaptive sliding observer [30, 31], an observer based on extended Kalman filter (EKF) [32], a hybrid current-voltage model estimator [33-35], and so forth. The adaptive observers aforementioned are complicated, and a few unknown parameters need to be tuned before working. Consequently, a full-order state observer in $d q$ coordinate is used to estimate the stator flux in this paper.

Referring to the analysis above, few DTC schemes possessing low torque ripple output can be directly applied to the IPMSM without increasing the complexity of the algorithms besides the PI-SVM DTC scheme [6, 25]. However, the PI controller in the PI-SVM DTC scheme degrades the dynamic response of the system. As a result, proposing a simple control strategy applicable to the IPMSM drive, which has lower torque ripple output and faster dynamic response, is of the essence.

The direct stator flux vector control is proposed in this paper to fill the gap. For the proposed scheme, the PI controller is removed from the torque control loop. Extracting the phase angle and amplitude of the stator flux from the estimated results is not necessary, and estimating the output torque is bypassed. The output of the speed outer loop is treated as the desired torque angle instead of the desired output torque in this paper. The desired stator flux vector in $d q$ coordinate is directly derived from the position relationship between the stator and rotor flux with a given stator flux amplitude. The discrete-time state-space equations for the IPMSM in $d q$ coordinate are established without using the extended electromotive force model [36]. Subsequently, the state feedback gain matrix is regulated by a variable to obtain a satisfied control performance, and a full-order state observer is designed to achieve a closedloop estimation for the actual stator flux in deadbeat manner. And then, the stator flux error vector is employed to calculate the desired stator voltage vector, which will be synthesized by the SVM. The proposed control scheme is experimentally verified on a two-level inverter fed IPMSM drive system.

\section{Mathematical Model of IPMSM}

\subsection{Mathematical model for IPMSM in continuous time domain}

The dynamic model for IPMSM in $d q$ coordinate is expressed as

$$
\begin{aligned}
& u_{s d}=R_{s} i_{s d}+\frac{\mathrm{d} \psi_{s d}}{\mathrm{~d} t}-\omega_{r} \psi_{s q} \\
& u_{s q}=R_{s} i_{s q}+\frac{\mathrm{d} \psi_{s q}}{\mathrm{~d} t}+\omega_{r} \psi_{s d}
\end{aligned}
$$

where $u_{s d}, u_{s q}$ are the $d$-and $q$-axis components of the stator voltage respectively, $i_{s d}, i_{s q}$ are the $d$ - and $q$-axis components of the stator current respectively, $\psi_{s d}, \psi_{s q}$ are the $d$ - and $q$-axis components of the stator flux respectively, $R_{s}$ is the stator resistance, and $\omega_{r}$ is the rotor electrical angular velocity.

The stator flux equations in $d q$ coordinate are shown as

$$
\begin{aligned}
& \psi_{s d}=L_{d} i_{s d}+\psi_{f} \\
& \psi_{s q}=L_{q} i_{s q}
\end{aligned}
$$

where $L_{d}, L_{q}$ are the $d$ - and $q$-axis inductances of IPMSM respectively, $\psi_{f}$ is the permanent magnet flux.

Convert (2) to get the stator current functions with respect to the stator flux

$$
\begin{aligned}
& i_{s d}=\frac{\psi_{s d}-\psi_{f}}{L_{d}} \\
& i_{s q}=\frac{\psi_{s q}}{L_{q}}
\end{aligned}
$$

Substitute (3) into (1), the stator flux differential equations are written as

$$
\begin{aligned}
& \frac{\mathrm{d} \psi_{s d}}{\mathrm{~d} t}=-\frac{R_{s}}{L_{d}}\left(\psi_{s d}-\psi_{f}\right)+\omega_{r} \psi_{s q}+u_{s d} \\
& \frac{\mathrm{d} \psi_{s q}}{\mathrm{~d} t}=-\omega_{r} \psi_{s d}-\frac{R_{s}}{L_{q}} \psi_{s q}+u_{s q}
\end{aligned}
$$

Define $\psi_{s d}^{\prime}=\psi_{s d}-\psi_{f}$ and $u_{s q}^{\prime}=u_{s q}-\omega_{r} \psi_{f}$, and revise (4), then the state equation for IPMSM is expressed as

$$
\left[\begin{array}{c}
\frac{\mathrm{d} \psi_{s d}^{\prime}}{\mathrm{d} t} \\
\frac{\mathrm{d} \psi_{s q}}{\mathrm{~d} t}
\end{array}\right]=\left[\begin{array}{cc}
-\frac{R_{s}}{L_{d}} & \omega_{r} \\
-\omega_{r} & -\frac{R_{s}}{L_{q}}
\end{array}\right]\left[\begin{array}{l}
\psi_{s d}^{\prime} \\
\psi_{s q}
\end{array}\right]+\left[\begin{array}{ll}
1 & 0 \\
0 & 1
\end{array}\right]\left[\begin{array}{l}
u_{s d} \\
u_{s q}^{\prime}
\end{array}\right]
$$


The output equation for IPMSM is chosen as

$$
\left[\begin{array}{l}
i_{s d} \\
i_{s q}
\end{array}\right]=\left[\begin{array}{cc}
\frac{1}{L_{d}} & 0 \\
0 & \frac{1}{L_{q}}
\end{array}\right]\left[\begin{array}{l}
\psi_{s d}^{\prime} \\
\psi_{s q}
\end{array}\right]
$$

For the convenience of the following analysis, the statespace representation for IPMSM is symbolically denoted as

$$
\begin{gathered}
\dot{\mathbf{x}}(t)=\mathbf{A}(t) \mathbf{x}(t)+\mathbf{B u}(t) \\
\mathbf{y}(t)=\mathbf{C} \mathbf{x}(t) \\
\mathbf{A}(t)=\left[\begin{array}{rr}
-\frac{R_{s}}{L_{d}} & \omega_{r} \\
-\omega_{r} & -\frac{R_{s}}{L_{q}}
\end{array}\right], \mathbf{B}=\left[\begin{array}{ll}
1 & 0 \\
0 & 1
\end{array}\right], \mathbf{C}=\left[\begin{array}{cc}
\frac{1}{L_{d}} & 0 \\
0 & \frac{1}{L_{q}}
\end{array}\right]
\end{gathered}
$$

where $\boldsymbol{x}(t)=\left[\begin{array}{ll}\psi_{s d}^{\prime} & \psi_{s q}\end{array}\right]^{\mathrm{T}}$ is the state vector, $\boldsymbol{u}(t)=\left[\begin{array}{ll}u_{s d} & u_{s q}^{\prime}\end{array}\right]^{\mathrm{T}}$ is the input vector, and $y(t)=\left[i_{s d} i_{s q}\right]^{\mathrm{T}}$ is the output vector. For the parameter $\omega_{r}$ is regarded as a time-varying quantity, state matrix $\mathbf{A}(t)$ is considered to be time-varying. $\mathbf{B}$ is the input matrix, and $\mathbf{C}$ is the output matrix.

The electromagnetic torque is displayed as follows

$$
\begin{aligned}
T_{e} & =\frac{3}{2} p\left(\psi_{s d} i_{s q}-\psi_{s q} i_{s d}\right) \\
& =\frac{3 p\left|\psi_{s}\right|}{4 L_{d} L_{q}}\left[2 \psi_{f} L_{q} \sin \delta+\left|\psi_{s}\right|\left(L_{d}-L_{q}\right) \sin 2 \delta\right]
\end{aligned}
$$

where $\left|\psi_{s}\right|$ is the amplitude of stator flux vector, $p$ is the pole pairs of IPMSM, and $\delta$ is the torque angle which is the angle between stator and rotor flux vector. Equation (9) shows that the electromagnetic torque contains two parts: the permanent magnet torque and the reluctance torque produced by the salient rotor.

And then, the torque derivative $k_{\mathrm{Te}}$ with respect to the torque angle $\delta$ is obtained

$$
\begin{aligned}
k_{T e} & =\frac{\mathrm{d} T_{e}}{\mathrm{~d} \delta} \\
& =\frac{3 p\left|\psi_{s}\right|}{2 L_{d} L_{q}}\left[\psi_{f} L_{q} \cos \delta+\left|\psi_{s}\right|\left(L_{d}-L_{q}\right) \cos 2 \delta\right]
\end{aligned}
$$

As to the IPMSM, some requirements revealed in [12, 13] should be fulfilled to realize the torque control through controlling the torque angle $\delta$

$$
\begin{gathered}
\left|\psi_{s}\right|<\frac{L_{q}}{L_{q}-L_{d}} \psi_{f} \\
\delta<\arccos \left[\frac{1}{4}\left(a-\sqrt{a^{2}+8}\right)\right]
\end{gathered}
$$

$$
a=\frac{\psi_{f} L_{q}}{\left|\psi_{s}\right|\left(L_{q}-L_{d}\right)}
$$

In this paper, the stator flux amplitude $\left|\psi_{s}\right|$ is chosen to be equal to the permanent magnet flux $\psi_{f}$.

The torque derivative with respect to the time $t$ is written as

$$
\begin{aligned}
\frac{\mathrm{d} T_{e}}{\mathrm{~d} t}= & \frac{3}{2} p\left\{\left[\frac{\psi_{f}}{L_{d}} \sin \delta+\frac{\left|\psi_{s}\right|\left(L_{d}-L_{q}\right) \sin 2 \delta}{L_{d} L_{q}}\right] \frac{\mathrm{d}\left|\psi_{s}\right|}{\mathrm{d} t}+\right. \\
& {\left.\left[\frac{\left|\psi_{s}\right| \psi_{f}}{L_{d}} \cos \delta+\frac{\left|\psi_{s}\right|^{2}\left(L_{d}-L_{q}\right) \cos 2 \delta}{L_{d} L_{q}}\right] \frac{\mathrm{d} \delta}{\mathrm{d} t}\right\} }
\end{aligned}
$$

According to (14), disregarding the parameter changes of IPMSM, the torque fluctuation implies the stator flux amplitude change or the torque angle variation. With the information of the rotor flux vector, the fluctuation of the stator flux vector is acquired. If the fluctuating quantity of the stator flux vector is controlled very small, the output torque ripple will be very small. Thus, the direct stator flux vector control is proposed in this paper to achieve a lower torque ripple output.

\subsection{State-space equations for IPMSM in discrete-time}

For digitally controlled IPMSM, the state-space equations for IPMSM in continuous time shown in (5) and (6) need to be converted into the discrete-time domain. By choosing a sampling period $T_{s}$, which is sufficiently small when compared with the significant time constant of IPMSM, the state-space equations for IPMSM in discrete-time domain are written as follows with assumption that the input vector $\boldsymbol{u}(k)$ is constant for $k T_{s} \leq t<(k+1) T_{s}$.

$$
\begin{gathered}
\mathrm{x}(k+1)=\mathbf{G}(k) \mathrm{x}(k)+\mathbf{H u}(k) \\
\mathrm{y}(k)=\mathbf{C x}(k)
\end{gathered}
$$

where the vectors $\boldsymbol{x}(k), \boldsymbol{u}(k)$ and $\boldsymbol{y}(k)$ represent the vector values at $k$ th sampling instant. Matrices $\mathbf{G}(k), \mathbf{H}$ and $\mathbf{C}$ are shown as

$$
\begin{gathered}
\mathbf{G}(k) \approx \mathbf{I}+\mathbf{A}(k) T_{s}=\left[\begin{array}{cc}
1-T_{s} \frac{R_{s}}{L_{d}} & T_{s} \omega_{r} \\
-T_{s} \omega_{r} & 1-T_{s} \frac{R_{s}}{L_{q}}
\end{array}\right] \\
\mathbf{H} \approx T_{s} \mathbf{B}=\left[\begin{array}{cc}
T_{s} & 0 \\
0 & T_{s}
\end{array}\right] \\
\mathbf{C}=\left[\begin{array}{cc}
\frac{1}{L_{d}} & 0 \\
0 & \frac{1}{L_{q}}
\end{array}\right]
\end{gathered}
$$




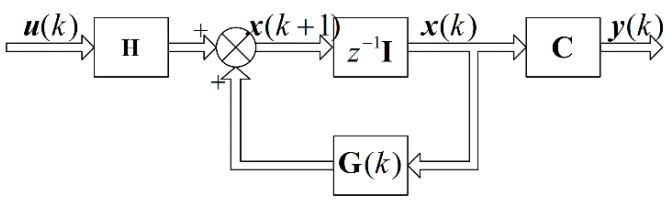

Fig. 1. Block diagram of the discrete-time IPMSM model in state space

where I is the identity matrix, $\mathbf{A}(k)$ denotes the value of matrix $\mathbf{A}(t)$ at $k$ th sampling instant. Fig. 1 illustrates the block diagram representation of the discrete-time IPMSM model.

In what follows, the direct stator flux vector control will be carried out by using the design method based on pole placement coupled with state observer.

\section{Implementation of Direct Stator Flux Vector Control}

It has been revealed by (14) that with the ignorance of the motor parameter variations, the torque error is involved with the stator flux error vector. With the known stator flux error vector, the desired stator voltage vector can be calculated according to the relationship between the stator voltage and stator flux vector pointed out by (4). The schematic diagram of the direct stator flux vector control for IPMSM is exhibited in Fig. 2.

As shown in Fig. 2, the output of the speed outer loop services as the value of the desired torque angle $\delta^{*}$ which becomes a constant in steady state. Then, the desired stator flux vector in $d q$ coordinate is obtained by using the desired stator flux vector calculator module with a given stator flux amplitude. Next, the state-space design is adopted to realize the closed-loop control of the stator flux vector in discrete time: the state feedback gain matrix $\mathbf{K}_{2}$ is designed to place the poles of the closed-loop system at the desired locations, a full-order state observer is applied to achieve a closed-loop estimation of the actual stator flux in deadbeat manner. The notation $\hat{\psi}_{s}$ represents the estimated result of the state observer, and matrices $\mathbf{N}_{\mathbf{u}}$ and $\mathbf{N}_{\mathbf{x}}$ are devised to follow the changing

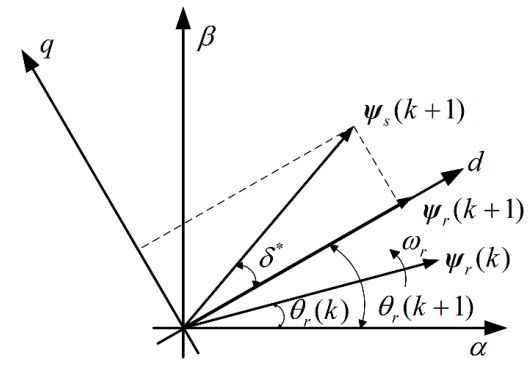

Fig. 3. Position relationship between the stator and rotor flux vector in discrete-time

reference inputs of stator flux.

\subsection{Desired stator flux vector calculator}

The spatial position relationship between the stator and rotor flux vector is depicted in Fig. 3. Define the rotor flux vector $\psi_{r}=\psi_{f} \mathrm{e}^{\mathrm{j} \theta r}$. Assume the angle between the rotor flux vector and the $\alpha$-axis of the stationary coordinate at $k$ th sampling instant is $\theta_{r}(k)$ and the one at $(k+1)$ th sampling instant is $\theta_{r}(k+1)$. The desired torque angle $\delta^{*}$, the angle between the stator and rotor flux vector at $(k+1)$ th sampling instant shown in Fig. 3, will be given by the speed outer loop. Thus, the desired $d-q$ axis components of the stator flux vector, i.e. the values at $(k+1)$ th sampling instant, will be developed with the preset desired stator flux amplitude as follows

$$
\begin{aligned}
& \psi_{s d}^{*}=\psi_{s d}(k+1)=\left|\psi_{s}\right|^{*} \cos \delta^{*} \\
& \psi_{s q}^{*}=\psi_{s q}(k+1)=\left|\psi_{s}\right|^{*} \sin \delta^{*}
\end{aligned}
$$

After modifying the elements, the desired state vector for IPMSM becomes

$$
\begin{aligned}
& \psi_{s}^{*}=\psi_{s}(k+1) \\
& =\left[\left|\psi_{s}\right|^{*} \cos \delta^{*}-\psi_{f}\left|\psi_{s}\right|^{*} \sin \delta^{*}\right]^{\mathrm{T}}
\end{aligned}
$$

\subsection{Pole placement for the closed-loop system}

As it has been demonstrated that the closed-loop poles of

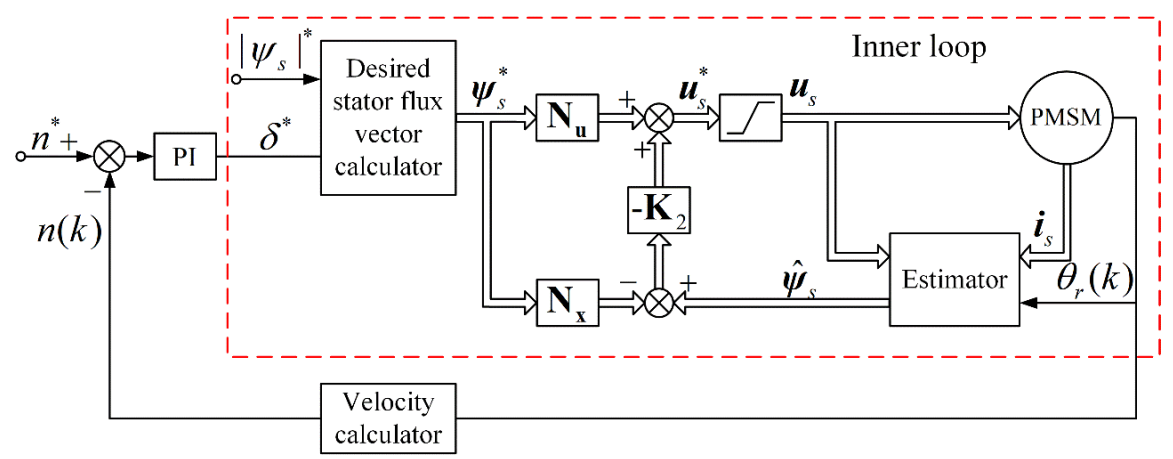

Fig. 2. Schematic diagram of direct stator flux vector control for IPMSM 


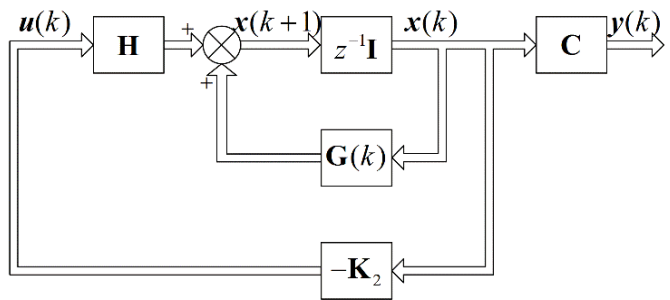

Fig. 4. State feedback control system for IPMSM

the observed-state feedback control system consist of the poles due to the pole placement design alone plus the poles due to the observer design alone, the pole placement design and the observer design can be developed separately and combined to form the observed-state feedback control system. Accordingly, the pole placement design for IPMSM is firstly developed with assumption that the stator flux $d-q$ axis components are available for feedback.

First of all, examine the rank of the controllability $\operatorname{matrix}[\mathbf{H}: \mathbf{G}(k) \mathbf{H}]$.

$$
\operatorname{rank}[\mathbf{H}: \mathbf{G}(k) \mathbf{H}]=2
$$

Hence, the IPMSM is completely state controllable, which is the necessary and sufficient condition to place the poles of the closed-loop system at any desired locations. On the basis of the open-loop control system displayed in Fig. 1, the closed-loop control system is organized by selecting the control vector $\boldsymbol{u}(k)=-\mathbf{K}_{2} \boldsymbol{x}(k)$, as shown in Fig. 4.

Noting that the characteristic equation of the original system described by (15) is

$$
\begin{aligned}
|z \mathbf{I}-\mathbf{G}(k)|= & z^{2}+\left[T_{s} R_{s}\left(\frac{1}{L_{d}}+\frac{1}{L_{q}}\right)-2\right] z \\
& +\left(\frac{T_{s} R_{s}}{L_{d}}-1\right)\left(\frac{T_{s} R_{s}}{L_{q}}-1\right)+\left(T_{s} \omega_{r}\right)^{2}
\end{aligned}
$$

The eigenvalues of $\mathbf{G}(k)$ are involved with the electrical angular velocity of the motor. However, the influence of the electrical angular velocity $\omega_{r}$ on the system can be avoided by choosing an appropriate state feedback gain matrix $\mathbf{K}_{2}$. As the determination of the state feedback gain matrix $\mathbf{K}_{2}$ is based on a compromise between the rapidity of the error vector response and the sensitivity to disturbances and measurement noises, it is a sensible choice to choose the gain matrix $\mathbf{K}_{2}$ in the following form, where an undetermined quantity $m$ is obligated for the convenience of regulation.

$$
\mathbf{K}_{2}=\left[\begin{array}{cc}
(m-1) \frac{R_{s}}{L_{d}} & \omega_{r} \\
-\omega_{r} & (m-1) \frac{R_{s}}{L_{q}}
\end{array}\right]
$$

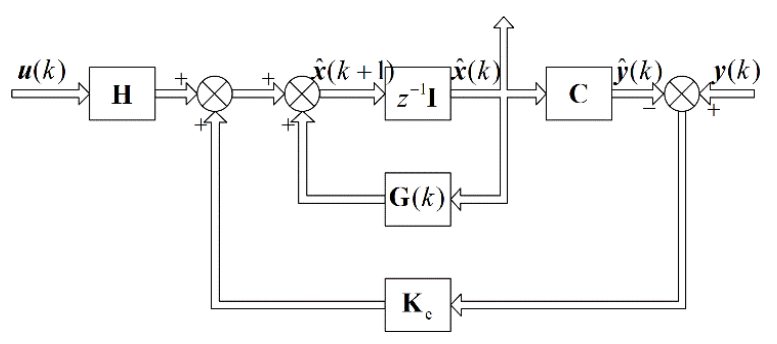

Fig. 5. Schematic diagram of the full-order stator flux observer

Substitute $\mathbf{K}_{2}$ into the characteristic equation of the closed-loop system

$$
\left|z \mathbf{I}-\mathbf{G}(k)+\mathbf{H} \mathbf{K}_{2}\right|=\left(z+m \frac{T_{s} R_{s}}{L_{q}}-1\right)\left(z+m \frac{T_{s} R_{s}}{L_{d}}-1\right)
$$

Referring to (25), it is shown that the eigenvalues of the closed-loop system can be moved along the positive real $z$-axis in the $z$-plane by varying the parameter $m$ over a range, which turns out to be an easy way to regulate the closed-loop system and obtain a good overall system performance.

\subsection{Full-order state observer for the stator flux}

For the stator flux of IPMSM cannot be directly measured, a full-order state observer is utilized in this paper to estimate the stator flux from the measurable output and input variables. Since the state observers can be designed if and only if the observability condition is satisfied, the observability of the system should be examined firstly. As matrix $\mathbf{G}(k)$ is confirmed to be nonsingular for the nonzero determinant, the equivalent condition exists as follows.

$$
\operatorname{rank}\left[\begin{array}{c}
\mathbf{C G}(k) \\
\mathbf{C}
\end{array}\right]=2
$$

Thus, the system is completely observable. The schematic diagram of a full-order stator flux observer is described in Fig. 5. The symbol $\mathbf{K}_{\mathrm{e}}$ means the observer feedback gain matrix, and the notations $\hat{x}(k)$ and $\hat{y}(k)$ respectively represent the estimated values of the state variables and output variables at $k$ th sampling instant. From Fig. 5, the difference between the measured output and the estimated output is added to the dynamic model to reduce the difference between the dynamic model and the actual system, thus the dynamic model of the state observer is expressed as

$$
\hat{\mathrm{x}}(k+1)=\mathbf{G}(k) \hat{\mathrm{x}}(k)+\mathbf{H u}(k)+\mathbf{K}_{e}[\mathrm{y}(k)-\hat{\mathrm{y}}(k)]
$$

Replace the estimated output vector $\hat{\mathrm{y}}(k)$ with $\mathbf{C} \hat{\mathrm{x}}(k)$, 
and then (27) is modified as

$$
\hat{\mathbf{x}}(k+1)=\left[\mathbf{G}(k)-\mathbf{K}_{e} \mathbf{C}\right] \hat{\mathbf{x}}(k)+\mathbf{H u}(k)+\mathbf{K}_{e} \mathrm{y}(k)
$$

Define the difference between $\boldsymbol{x}(k)$ and $\hat{\mathrm{x}}(k)$ as the error vector $\boldsymbol{e}(k)$ :

$$
\mathrm{e}(k)=\mathrm{x}(k)-\hat{\mathrm{x}}(k)
$$

Consequently, the observer error equation is obtained

$$
\mathrm{e}(k+1)=\left[\mathbf{G}(k)-\mathbf{K}_{e} \mathbf{C}\right] \mathrm{e}(k)
$$

Based on (30), it can be found that the locations of the eigenvalues of $\mathbf{G}(k)-\mathbf{K}_{\mathrm{e}} \mathbf{C}$ determine the dynamic behavior of the error vector. Therefore, an appropriate observer feedback gain matrix $\mathbf{K}_{\mathrm{e}}$ should be chosen to make the error tend to zero with adequate speed. In the observedstate feedback control system, the poles of the observer are usually chosen in such a way that the observer response is much faster than the system response. Since the observer is, in general, not a hardware structure but is programmed on the digital controller, the deadbeat response is adopted in this paper so that the estimated state quickly converges to the true state.

Referring to (28), the characteristic equation of the observer is express as

$$
\left|z \mathbf{I}-\mathbf{G}(k)+\mathbf{K}_{e} \mathbf{C}\right|=0
$$

For this low-order system, it may be simpler to substitute

$$
\mathbf{K}_{e}=\left[\begin{array}{ll}
k_{1} & k_{2} \\
k_{3} & k_{4}
\end{array}\right]
$$

into the characteristic equation denoted by (31), and then the characteristic equation is equated with the desired characteristic equation. As all observer poles are located at the origin for deadbeat response, these undetermined parameters in the observer feedback gain matrix $\mathbf{K}_{\mathrm{e}}$ are selected as

$$
\begin{aligned}
& k_{1}=L_{d}-T_{s} R_{s}, k_{2}=T_{s} \omega_{r} L_{q} \\
& k_{3}=-T_{s} \omega_{r} L_{d}, \quad k_{4}=L_{q}-T_{s} R_{s}
\end{aligned}
$$

As a result, the desired state feedback gain matrix is given by

$$
\mathbf{K}_{e}=\left[\begin{array}{cc}
L_{d}-T_{s} R_{s} & T_{s} \omega_{r} L_{q} \\
-T_{s} \omega_{r} L_{d} & L_{q}-T_{s} R_{s}
\end{array}\right]
$$

Then, the estimated state $\hat{\mathbf{x}}(k)$ will be used to replace the immeasurable state variable $\boldsymbol{x}(k)$ to form the input vector

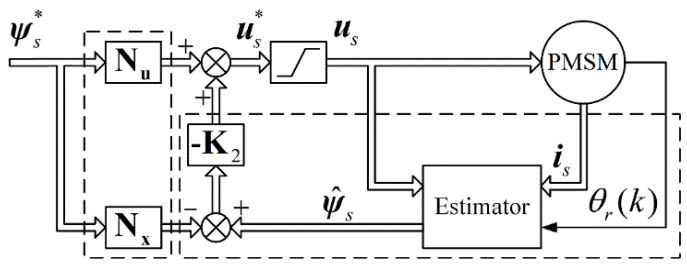

Fig. 6. Block diagram for introducing the reference input with observed-state feedback

$\boldsymbol{u}(k)$, as depicted in Fig. 2.

\subsection{Control system with reference input}

The desired stator flux vector, which has been calculated before, is introduced into the system as shown in Fig. 2, so that the control system must have a good command following ability. Thus, the control gain matrix $\mathbf{N}_{\mathbf{u}}$ and the state gain matrix $\mathbf{N}_{\mathbf{x}}$ exhibited in Fig. 6 are provided to make the system have a small steady-state error to a constant input.

If the desired final values of the state and the control input are $\boldsymbol{x}_{\mathrm{ss}}$ and $\boldsymbol{u}_{\mathrm{ss}}$ respectively, the command inputs $\boldsymbol{r}_{\mathrm{ss}}$ are equal to the final values of the state $\boldsymbol{x}_{\mathrm{ss}}$ in this paper. Define $\boldsymbol{x}_{\mathrm{ss}}=\mathbf{N}_{\mathrm{x}} \boldsymbol{r}_{\mathrm{ss}}$ and $\boldsymbol{u}_{\mathrm{ss}}=\mathbf{N}_{\mathrm{u}} \boldsymbol{r}_{\mathrm{ss}}$, the state gain matrix is shown as follows

$$
\mathbf{N}_{\mathbf{x}}=\left[\begin{array}{ll}
1 & 0 \\
0 & 1
\end{array}\right]
$$

In steady state, Eq. (15) is supposed to be

$$
\mathbf{x}_{s s}=\mathbf{G}(k) \mathbf{x}_{s s}+\mathbf{H} \mathbf{u}_{s s}
$$

And then (35) is simplified according to the discretization process displayed by (17) and(18).

$$
\mathbf{0}=\mathbf{A}(k) \mathbf{x}_{s s}+\mathbf{B} \mathbf{u}_{s s}
$$

Substitute $\boldsymbol{x}_{\mathrm{ss}}=\mathbf{N}_{\mathrm{x}} \boldsymbol{r}_{\mathrm{ss}}$ and $\boldsymbol{u}_{\mathrm{ss}}=\mathbf{N}_{\mathrm{u}} \boldsymbol{r}_{\mathrm{ss}}$ into (36), the control gain matrix is solved as

$$
\mathbf{N}_{\mathbf{u}}=-\mathbf{A}(k)=\left[\begin{array}{cc}
\frac{R_{s}}{L_{d}} & -\omega_{r} \\
\omega_{r} & \frac{R_{s}}{L_{q}}
\end{array}\right]
$$

In what follows, the desired input vector is derived

$$
\begin{aligned}
\mathbf{u}^{*}(k) & =\mathbf{N}_{\mathbf{u}} \mathbf{r}-\mathbf{K}_{2}\left[\hat{\mathbf{x}}(k)-\mathbf{N}_{\mathbf{x}} \mathbf{r}\right] \\
& =-\mathbf{K}_{2} \hat{\mathbf{x}}(k)+\left(\mathbf{N}_{\mathbf{u}}+\mathbf{K}_{2} \mathbf{N}_{\mathbf{x}}\right) \mathrm{r}
\end{aligned}
$$

Namely, 
$\left[\begin{array}{l}u_{s d}^{*} \\ u_{s q}^{\prime *}\end{array}\right]=-\left[\begin{array}{cc}(m-1) \frac{R_{s}}{L_{d}} & \omega_{r} \\ -\omega_{r} & (m-1) \frac{R_{s}}{L_{q}}\end{array}\right]\left[\begin{array}{l}\hat{\psi}_{s d}^{\prime} \\ \hat{\psi}_{s q}\end{array}\right]+\left[\begin{array}{cc}m \frac{R_{s}}{L_{d}} & 0 \\ 0 & m \frac{R_{s}}{L_{q}}\end{array}\right]\left[\begin{array}{l}\psi_{s d}^{\prime *} \\ \psi_{s q}^{*}\end{array}\right]$

The desired voltage vector needs to be modified in the following form before sent to the SVM module.

$$
\left[\begin{array}{l}
u_{s d}^{*} \\
u_{s q}^{*}
\end{array}\right]=\left[\begin{array}{l}
u_{s d}^{*} \\
u_{s q}^{\prime *}
\end{array}\right]+\left[\begin{array}{c}
0 \\
\omega_{r} \psi_{f}
\end{array}\right]
$$

Considering that the magnitude of the input vector $\boldsymbol{u}(k)$ is not unbounded, which is limited by the DC-link voltage of the converter, a saturation nonlinearity module is included in the feed-forward path to denote partial function of the SVM module as shown in Fig. 6.

\section{Experimental Results}

A $5 \mathrm{~kW}$ experimental prototype was constructed to verify the effectiveness of the proposed direct stator flux vector control as shown in Fig. 7. A TMS320F2808 DSP board is used to implement the algorithms mentioned above, and a switching power supply board is adopted as a power supply for the DSP board. A $7.5 \mathrm{~kW}$ IPMSM and a $5 \mathrm{~kW}$ interior permanent magnet synchronous generator (IPMSG) make up the experimental drive system. Since all experiments are focused on the IPMSM, the control of the IPMSG is neglected in this paper. Detailed parameters of the IPMSM are listed in Table 1. A 10000 pulses per revolution (PPR) incremental encoder with quadratic decoding method is utilized to provide the rotor mechanical position. A YOKOGAWA DLM2024 oscilloscope is used to measure the input currents. The actual output torque and the estimated stator flux in the control system are transmitted from the DSP by a PCAN-USB interface. The sampling frequency of the control systems is $10 \mathrm{kHz}$, and the DClink voltage is $500 \mathrm{~V}$. The PI-SVM DTC scheme proposed in $[6,25]$ is also tested on the same experimental prototype

Table 1. Parameters of the IPMSM in experiment

\begin{tabular}{c|c|c}
\hline Parameters & Symbols & Values \\
Number of pole pairs & $p$ & 8 \\
Rated power (kW) & $P_{\mathrm{N}}$ & 7.5 \\
Rated current-RMS (A) & $I_{\mathrm{N}}$ & 13.4 \\
Rated voltage-RMS (V) & $U_{\mathrm{N}}$ & 380 \\
Rated torque (Nm) & $T_{\mathrm{e}}$ & 895 \\
Rated speed (r/min) & $n_{\mathrm{N}}$ & 80 \\
Rated frequency $(\mathrm{Hz})$ & $f_{\mathrm{N}}$ & 10.667 \\
d-axis inductance $(\mathrm{mH})$ & $L_{d}$ & 34.33 \\
q-axis inductance $(\mathrm{mH})$ & $L_{q}$ & 50.77 \\
Stator phase resistance $(\Omega)$ & $R_{s}$ & 1.573 \\
Permanent-magnet flux $(\mathrm{Wb})$ & $\Psi_{f}$ & 4.80652 \\
Mechanical inertia $\left(\mathrm{kg} . \mathrm{m}^{2}\right)$ & $J$ & 1.6 \\
\hline
\end{tabular}

to make a comparison with the scheme proposed in this paper.

\subsection{Inner loop operation}

In order to test the dynamic performance of the direct stator flux vector control scheme, i.e. the inner loop displayed in Fig. 2, the IPMSG driven by a YASKAWA A1000 inverter operates in motor mode while the IPMSM fed by the experimental prototype works in generator mode. The running speed of the driven system is controlled by the IPMSG side. To make a comparative study, the PI-SVM DTC strategy which employs the same full-order state observer is implemented on the IPMSM.

The estimated results of the stator flux based on the full-

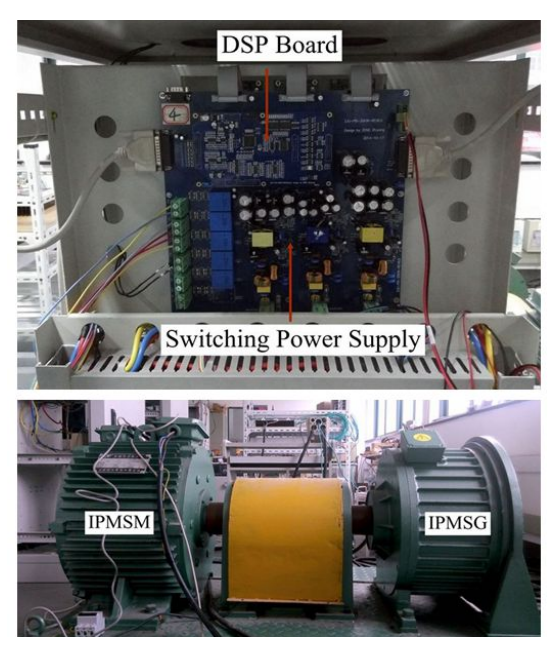

Fig. 7. A $5 \mathrm{~kW}$ experimental prototype.

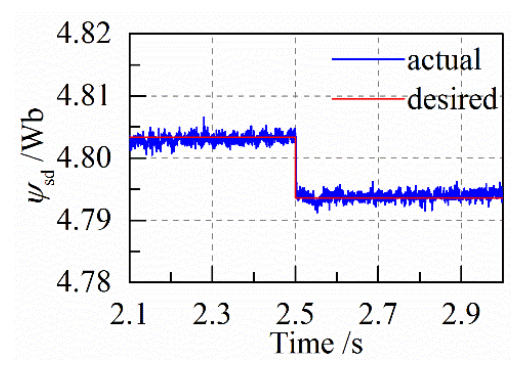

(a) the stator flux d-axis component $\psi_{s d}$

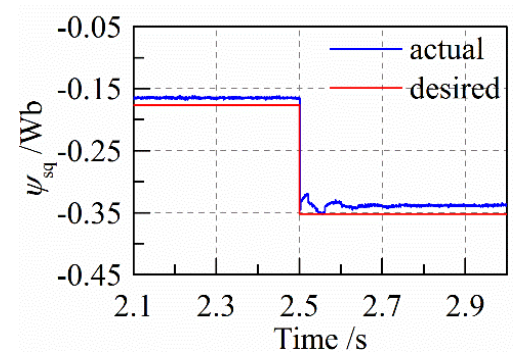

(b) the stator flux q-axis component $\psi_{s q}$

Fig. 8. Estimated results of the stator flux vector based on the full-order state observer. 
order state observer at the running speed $n=37.5 \mathrm{r} / \mathrm{min}$ is presented in Fig. 8. When the desired torque angle $\delta^{*}$ steps from -0.03664 to $-0.07334 \mathrm{rad}$, the estimated stator flux nearly steps to follow the desired values in addition to a $-0.01 \mathrm{~Wb}$ estimation error in the stator flux q-axis component.

When the given torque steps from -200 to $-400 \mathrm{Nm}$, i.e. the desired torque angle $\delta^{*}$ steps from -0.03664 to -0.07334 $\mathrm{rad}$, the experimental results of the output torque and threephase current at the running speed $n=37.5 \mathrm{r} / \mathrm{min}$ for both schemes are exhibited in Figs. 9 and 10 respectively. The torque dynamic process for both schemes are enlarged in Fig. 9(b) and Fig. 10(b) respectively. The output torque fluctuation exists in Fig. 9(a) for 0.1 seconds, and the rise time for the torque in Fig. 9(b) is about 2 milliseconds, which will be extended if improper PI parameters are set. The torque transient process decays in only 0.07 seconds for the direct stator flux vector control as revealed in Fig. 10(a), and the rise time for the torque in Fig. 10(b) is about 1 milliseconds. Moreover, an overshoot about $-40 \mathrm{Nm}$ exists in Fig. 9(b), while no obvious overshoot presented in

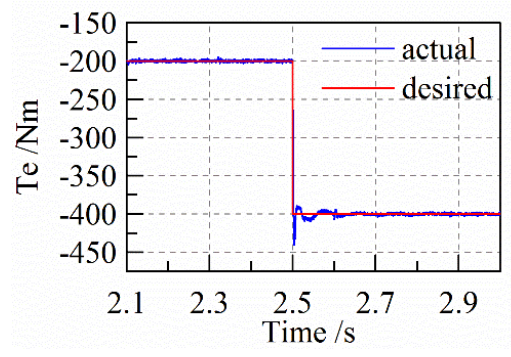

(a) the torque output

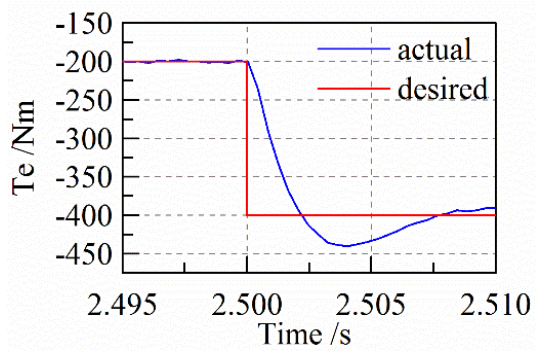

(b) enlargement of the torque dynamic process

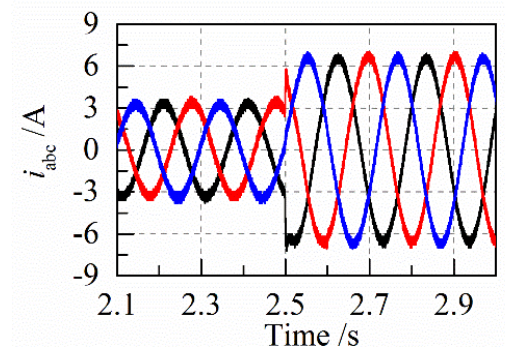

(c) the three-phase current output

Fig. 9. Experimental results of the PI-SVM DTC at $n=37.5$ $\mathrm{r} / \mathrm{min}$ when the given torque steps from -200 to -400 $\mathrm{Nm}$.
Fig. 10(b). The phase currents in Fig. 9(c) are gradually changed after the given torque steps while the phase currents almost step when desired torque angle $\delta^{*}$ steps in Fig. 10(c). The parameters of the PI controller and the pole placement variable $m$ are listed in Table 2 .

Due to the nonexistence of the integrator unit in the inner loop of the direct stator flux vector control scheme, the steady-state error to step input cannot be eliminated [37]. As displayed in Fig. 10a, a steady-state error about $20 \mathrm{Nm}$ emerges between the desired and actual output torque for the direct stator flux vector control.

According to the IPMSM parameters in Table 1, the torque derivative $k_{\mathrm{Te}}$ revealed by (10) is set to 5475 to simplify the calculation of the compensatory torque angle. To remove the $-20 \mathrm{Nm}$ torque error, a small compensatory

Table 2. Parameters of the controllers

\begin{tabular}{c|c|c}
\hline Parameters & Symbols & Values \\
\hline Proportional of PI-SVM & $k_{\mathrm{p}}$ & 0.0000582225 \\
\hline Integral of PI-SVM & $k_{\mathrm{i}}$ & 0.023289 \\
\hline Pole placement variable & $m$ & 60 \\
\hline
\end{tabular}

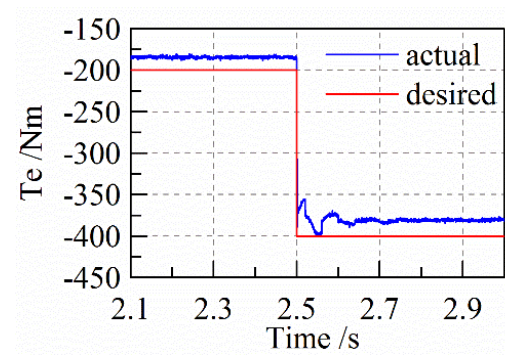

(a) the torque output

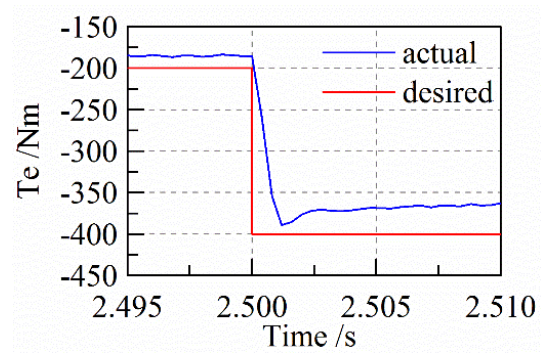

(b) enlargement of the torque dynamic process

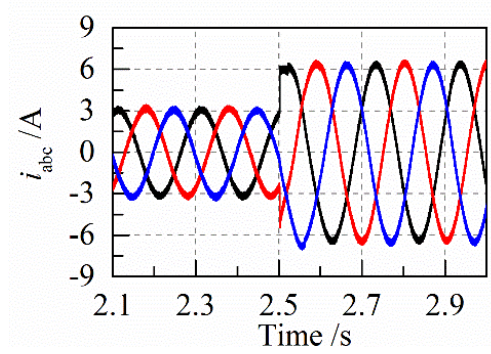

(c) the three-phase current output

Fig. 10. Experimental results of the direct stator flux vector control at $n=37.5 \mathrm{r} / \mathrm{min}$ when $\delta^{*}$ steps from -0.03664 to $-0.07334 \mathrm{rad}$. 


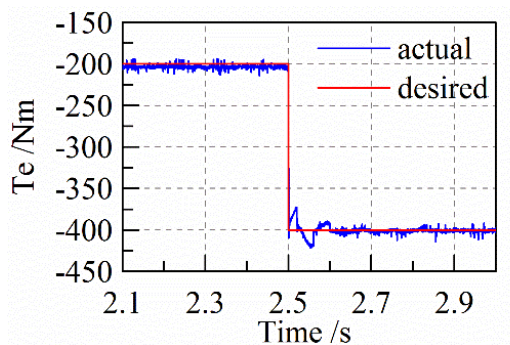

(a) the torque output

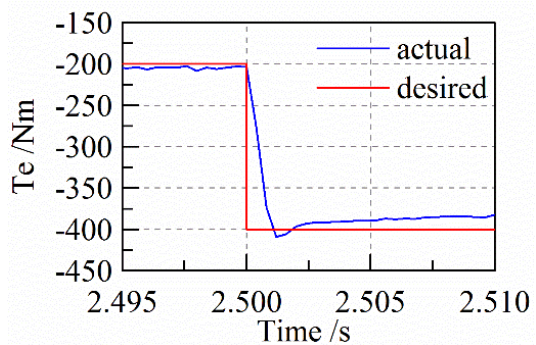

(b) enlargement of the torque dynamic process

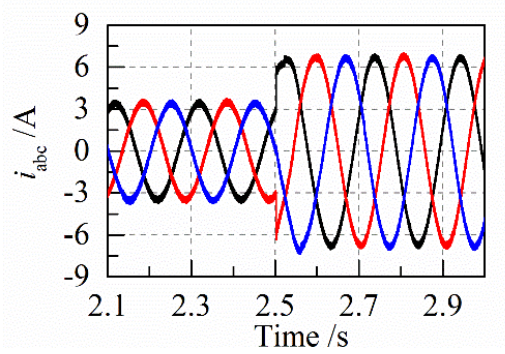

(c) the three-phase current output

Fig. 11. Experimental results of the direct stator flux vector control with a torque angle compensatory at $n=$ $37.5 \mathrm{r} / \mathrm{min}$ when $\delta^{*}$ steps from -0.03664 to -0.07334 rad.

torque angle $\Delta \delta=-20 / 5475=-0.003652968 \mathrm{rad}$ is added to the desired torque angle, and the output torque of the direct stator flux vector control reaches the desired value, as shown in Fig. 11(a). The enlargement of the torque dynamic process is displayed in Fig. 11(b), and the phase current output in Fig. 11(c) is nearly the same as the one in Fig, 10(c). According to the schematic diagram depicted in Fig. 2, the compensatory torque angle will be generated by the speed outer loop to make the IPMSM stably operate at the desired speed. Therefore, the torque output error presented in Fig. 10(a) can be neglected in the proposed scheme.

\subsection{Steady-state operation with speed outer loop}

To verify the output performance of the whole control system shown in Fig. 2, the speed outer loop control is added into the IPMSM control system to generate the desired torque angle $\delta^{*}$, and the IPMSG together with three $9 \Omega$ resistors directly connected to its stator terminals are

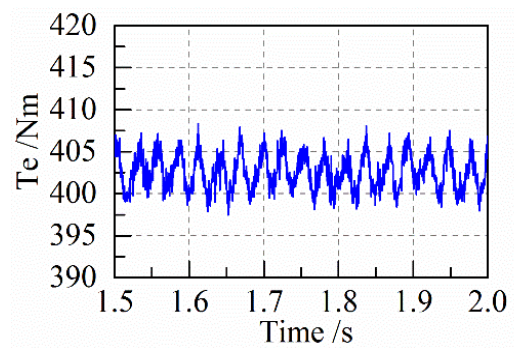

(a) the torque output

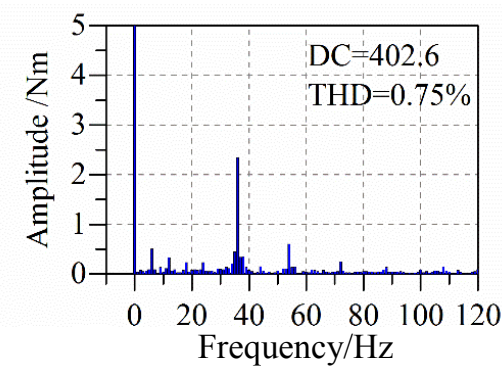

(b) FFT results of the torque output

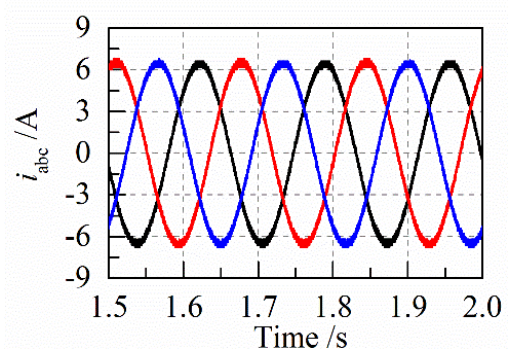

(c) the three-phase current output

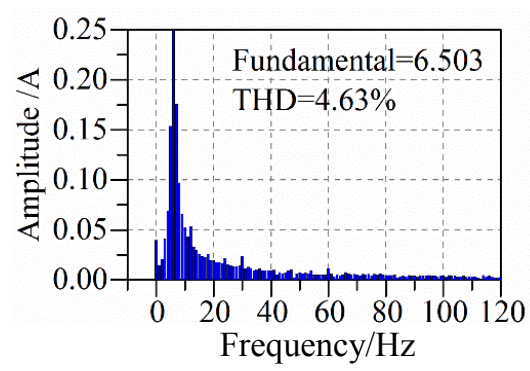

(d) FFT results of $i_{s a}$

Fig. 12. Experimental results of the PI-SVM DTC with the speed outer loop control at $n=45 \mathrm{r} / \mathrm{min}$.

used as the load. When the IPMSM stably runs at $n=45$ $\mathrm{r} / \mathrm{min}$, the torque and current outputs and the corresponding fast Fourier transformation (FFT) results for the PI-SVM DTC scheme are presented in Fig. 12, and those for the direct stator flux vector control scheme are exhibited in Fig. 13.

The torque outputs for both schemes under the same load conditions are shown in Fig. 12(a) and Fig 13(a), where a lower torque ripple output for the proposed direct stator flux vector control scheme is exhibited. The 


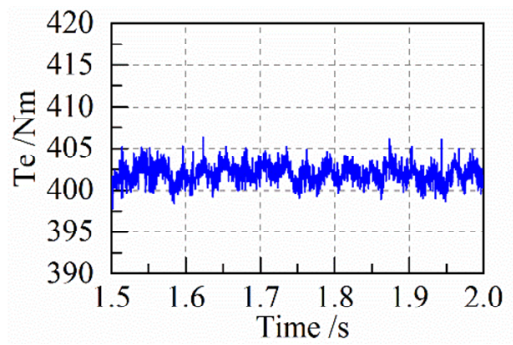

(a) the torque output

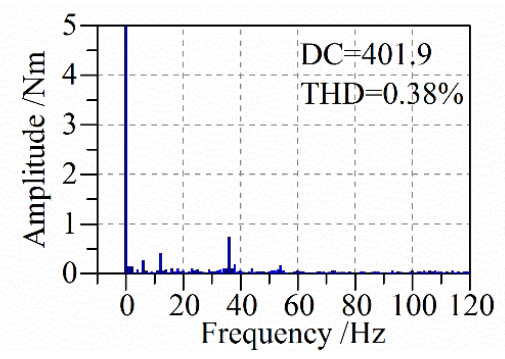

(b) FFT results of the torque output

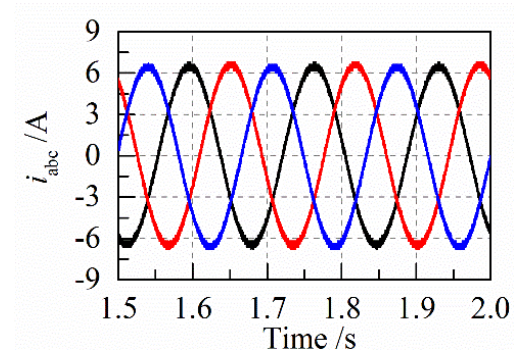

(c) the three-phase current output

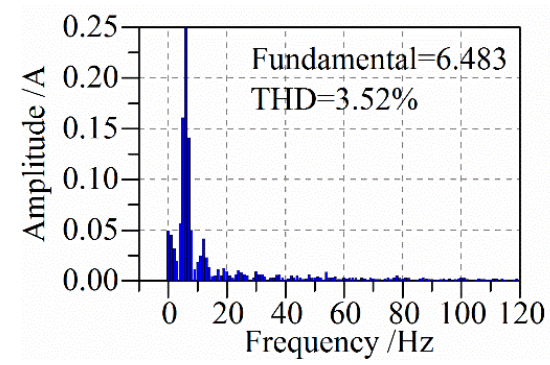

(d) FFT results of $i_{s a}$

Fig. 13. Experimental results of the direct stator flux vector control with the speed outer loop at $n=45 \mathrm{r} / \mathrm{min}$.

corresponding FFT results are shown in Figs. 12(b) and 13(b). The DC component of the torque outputs for both schemes are almost equal, and the proposed scheme has a lower total harmonic distortion (THD) outputs than the PI-SVM DTC especially for the 6th harmonic. The threephase current outputs for both schemes are displayed in Figs. 12(c) and 13(c) respectively, and the relevant FFT results of $i_{s a}$ are shown in Figs. 12(d) and 13(d). The fundamental component amplitudes of $i_{s a}$ for both schemes are almost identical to each other. Compared with the PISVM DTC, the proposed scheme has a lower THD outputs

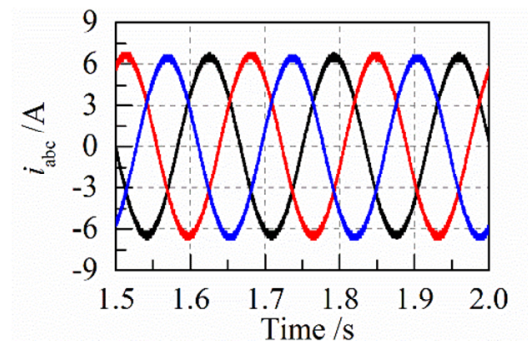

(a) the three-phase current output

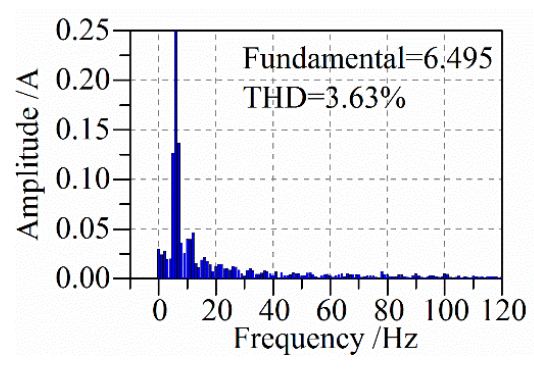

(b) FFT results of $i_{s a}$

Fig. 14. Experimental results of the direct stator flux vector control with the speed outer loop at $n=45 \mathrm{r} / \mathrm{min}$ when the parameters varied with $20 \%$ increase.

especially for the 5th harmonic. Since the DC component of the torque out and the fundamental component amplitude of the phase currents are almost the same, the compensatory torque angle used in Fig. 11 for the direct stator flux vector control scheme is correctly generated by the speed outer loop, and the steady-state torque error at a given load condition is eliminated. Consequently, the feasibility of the proposed direct stator flux vector control scheme has been verified.

\subsection{Parameter sensitivity}

Since many IPMSM parameters are involved in the proposed direct stator flux vector control scheme, the parameters of the IPMSM listed in Table 1, namely $L_{d}, L_{q}$, $R_{s}$ and $\psi_{f}$, are varied with $20 \%$ increase and then applied in the DSP to examine the robustness of the proposed scheme. The experimental conditions used in subsection 4.2 are also adopted in this part, namely the same load conditions are implemented. In viewing of that the IPMSM torque output is calculated according to (9) in the DSP, it will be unreliable when the parameters changed. Consequently, only the directly measured threephase current of the IPMSM is exhibited in Fig. 14.

According to the FFT results shown in Fig. 14(b), the fundamental component amplitude of $i_{s a}$ when the parameters varied with $20 \%$ increase is almost equal to that in Fig. 13(d). Thus a strong robustness of the proposed scheme against the IPMSM parameter variations is exhibited. 


\section{Conclusion}

A direct stator flux vector control based on pole placement with state observer in discrete-time is proposed in this paper. The discrete-time IPMSM model in $d q$ coordinate for state-space control is deduced, and a fullorder state observer is constructed to observe the stator flux in deadbeat manner. A variable is obligated in the state feedback gain matrix to regulate the system control performance. By employing the output of the speed outer loop as the desired torque angle, the direct stator flux vector control is realized for the IPMSM drive. For the proposed scheme, the PI controller used in PI-SVM DTC scheme is avoided, and the torque differential equation is unwanted. Thus, a simple algorithm applicable to IPMSM is achieved, and faster dynamic response and lower torque ripple output are obtained. Experiment results have verified the effectiveness of the direct stator flux vector control scheme.

\section{References}

[1] J. A. Guemes, A. M. Iraolagoitia, J. I. Del Hoyo, and P. Fernandez, "Torque Analysis in Permanent-Magnet Synchronous Motors: A Comparative Study," IEEE Trans. Energy Convers., vol. 26, no. 1, pp. 55-63, Mar. 2011.

[2] S. Chung, J. Kim, Y. Chun, B. Woo, and D. Hong, "Fractional Slot Concentrated Winding PMSM With Consequent Pole Ro-tor for a Low-Speed Direct Drive: Reduction of Rare Earth Permanent Magnet," IEEE Trans. Energy Convers., vol. 30, no. 1, pp. 103109, Mar. 2015.

[3] G. S. Buja and M. P. Kazmierkowski, "Direct torque control of PWM inverter-fed AC motors - a survey," IEEE Trans. Ind. Electron., vol. 51, no. 4, pp. 744757, Aug. 2004.

[4] I. Takahashi and T. Noguchi, "A New QuickResponse and High-Efficiency Control Strategy Of An Induction-Motor," IEEE Trans. Ind. Appl., vol. IA-22, no. 5, pp. 820-827, Sep. 1986.

[5] M. Depenbrock, "Direct self-control (DSC) of inverter-fed induction machine," IEEE Trans. Power Electron., vol. 3, no. 4, pp. 420-429, Oct. 1988.

[6] Y. Inoue, S. Morimoto and M. Sanada, "Examination and Linearization of Torque Control System for Direct Torque Con-trolled IPMSM," IEEE Trans. Ind. Appl., vol. 46, no. 1, pp. 159-166, Jan./Feb. 2010.

[7] L. Zheng, J. E. Fletcher, B. W. Williams, and X. He, "A Novel Direct Torque Control Scheme for a Sensorless Five-Phase Induction Motor Drive," IEEE Trans. Ind. Electron., vol. 58, no. 2, pp. 503-513, Feb. 2011.

[8] T. H. Liu and H. H. Hsu, "Adaptive controller design for a synchronous reluctance motor drive system with direct torque control," IET Electr. Power Appl., vol. 1, no. 5, pp. 815-824, Sep. 2007.

[9] S. B. Ozturk, W. C. Alexander and H. A. Toliyat, "Direct Torque Control of Four-Switch Brushless DC Motor With Non-Sinusoidal Back EMF," IEEE Trans. Power Electron., vol. 25, no. 2, pp. 263-271, Feb. 2010.

[10] C. Patel, P. P. Rajeevan, A. Dey, R. Ramchand, K. Gopakumar, and M. P. Kazmierkowski, "Fast Direct Torque Control of an Open-End Induction Motor Drive Using 12-Sided Polygonal Voltage Space Vectors," IEEE Trans. Power Electron., vol. 27, no. 1, pp. 400-410, Jan. 2012.

[11] Y. Wang and Z. Deng, "Improved Stator Flux Estimation Method for Direct Torque Linear Control of Parallel Hybrid Excitation Switched-Flux Generator," IEEE Trans. Energy Convers., vol. 27, no. 3, pp. 747-756, Sep. 2012.

[12] L. Zhong, M. F. Rahman, W. Y. Hu, and K. W. Lim, "Analysis of direct torque control in permanent magnet synchronous motor drives," IEEE Trans. Power Electron., vol. 12, no. 3, pp. 528-536, May 1997.

[13] L. Zhong, M. F. Rahman, W. Y. Hu, K. W. Lim, and M. A. Rahman, "A direct torque controller for permanent magnet synchronous motor drives," IEEE Trans. Energy Convers., vol. 14, no. 3, pp. 637-642, Sep. 1999.

[14] D. Casadei, G. Serra and A. Tani, "Implementation of a direct control algorithm for induction motors based on discrete space vector modulation," IEEE Trans. Power Electron., vol. 15, no. 4, pp. 769-777, Jul 2000.

[15] Y. S. Lai, W. K. Wang and Yen-Chang Chen, "Novel switching techniques for reducing the speed ripple of AC drives with direct torque control," IEEE Trans. Ind. Electron., vol. 51, no. 4, pp. 768775, Aug. 2004.

[16] F. Khoucha, S. M. Lagoun, K. Marouani, A. Kheloui and M. E. H. Benbouzid, "Hybrid Cascaded HBridge Multilevel-Inverter Induction-Motor-Drive Direct Torque Control for Automotive Applications," IEEE Trans. Ind. Electron., vol. 57, no. 3, pp. 892899, Mar. 2010.

[17] D. Casadei, G. Serra and A. Tani, "The use of matrix converters in direct torque control of induction machines," IEEE Trans. Ind. Electron., vol. 48, no. 6, pp. 1057-1064, Dec. 2001.

[18] C. Xia, S. Wang, Z. Wang and T. Shi, "Direct Torque Control for VSI-PMSMs Using Four-Dimensional Switching-Table," IEEE Trans. Power Electron., vol. 31, no. 8, pp. 5774-5785, Aug. 2016.

[19] C. Xia, J. Zhao, Y. Yan and T. Shi, “A Novel Direct Torque Control of Matrix Converter-Fed PMSM Drives Using Duty Cycle Control for Torque Ripple Reduction," IEEE Trans. Ind. Electron., vol. 61, no. 6, 
pp. 2700-2713, Jun. 2014.

[20] J. K. Kang and S. K. Sul, "New direct torque control of induction motor for minimum torque ripple and constant switching frequency," IEEE Trans. Ind. Appl., vol. 35, no. 5, pp. 1076-1082, Sep./Oct. 1999.

[21] B. H. Kenny and R. D. Lorenz, "Stator- and rotorflux-based deadbeat direct torque control of induction machines," IEEE Trans. Ind. Appl., vol. 39, no. 4, pp. 1093-1101, Jul./Aug. 2003.

[22] T. G. Habetler, F. Profumo, M. Pastorelli, And L. M. Tolbert, "Direct Torque Control of Induction Machines Using Space Vector Modulation," IEEE Trans. Ind. Appl., vol. 28, no. 5, pp. 1045-1051, Sep./Oct. 1992.

[23] M. Pacas and J. Weber, "Predictive direct torque control for the PM synchronous machine," IEEE Trans. Ind. Electron., vol. 52, no. 5, pp. 1350-1356, Oct. 2005.

[24] N. Feng, L. Kui and W. Yao, "Direct Torque Control for Permanent-Magnet Synchronous Machines Based on Duty Ratio Modulation," IEEE Trans. Ind. Electron., vol. 62, no. 10, pp. 6160-6170, Oct. 2015.

[25] L. X. Tang, L. M. Zhong, M. F. Rahman, and Y. W. Hu, "A novel direct torque controlled interior permanent magnet synchronous machine drive with low ripple in flux and torque and fixed switching frequency," IEEE Trans. Power Electron., vol. 19, no. 2, pp. 346-354, Mar. 2004.

[26] Z. Xu and M. F. Rahman, "Direct torque and flux regulation of an IPM synchronous motor drive using variable structure control approach," IEEE Trans. Power Electron., vol. 22, no. 6, pp. 2487-2498, Nov. 2007.

[27] H. Zhu, X. Xiao and Y. Li, "Torque Ripple Reduction of the Torque Predictive Control Scheme for Permanent-Magnet Synchronous Motors," IEEE Trans. Ind. Electron., vol. 59, no. 2, pp. 871-877, Feb. 2012.

[28] Y. Zhang, J. Zhu, W. Xu, and Y. Guo, "A Simple Method to Reduce Torque Ripple in Direct TorqueControlled Permanent-Magnet Synchronous Motor by Using Vectors With Variable Amplitude and Angle," IEEE Trans. Ind. Electron., vol. 58, no. 7, pp. 2848-2859, Jul. 2011.

[29] R. Wu and G. R. Slemon, "A permanent magnet motor drive without a shaft sensor," IEEE Trans. Ind. Appl., vol. 27, no. 5, pp. 1005-1011, Sep./Oct. 1991.

[30] Z. Xu and M. F. Rahman, "An adaptive sliding stator flux observer for a direct-torque-controlled IPM synchronous motor drive," IEEE Trans. Ind. Electron., vol. 54, no. 5, pp. 2398-2406, Oct. 2007.

[31] G. H. B. Foo and M. F. Rahman, "Direct Torque Control of an IPM-Synchronous Motor Drive at Very Low Speed Using a Sliding-Mode Stator Flux Observer," IEEE Trans. Power Electron., vol. 25, no. 4, pp. 933-942, Apr. 2010.
[32] Z. Xu and M. F. Rahman, "Comparison of a Sliding Observer and a Kalman Filter for Direct-TorqueControlled IPM Synchronous Motor Drives," IEEE Trans. Ind. Electron., vol. 59, no. 11, pp. 4179-4188, Nov. 2012.

[33] G. Foo, S. Sayeef and M. F. Rahman, "Low-Speed and Standstill Operation of a Sensorless Direct Torque and Flux Controlled IPM Synchronous Motor Drive," IEEE Trans. Energy Convers., vol. 25, no. 1, pp. 25-33, Mar. 2010.

[34] W. Xu and R. D. Lorenz, "Reduced Parameter Sensitivity Stator Flux Linkage Observer in DeadbeatDirect Torque and Flux Control for IPMSMs," IEEE Trans. Ind. Appl., vol. 50, no. 4, pp. 2626-2636, Jul./ Aug. 2014.

[35] J. S. Lee, C. Choi, J. Seok, and R. D. Lorenz, "Deadbeat-Direct Torque and Flux Control of Interior Permanent Magnet Synchronous Machines with Discrete Time Stator Current and Stator Flux Linkage Observer," IEEE Trans. Ind. Appl., vol. 47, no. 4, pp. 1749-1758, Jul./Aug. 2011.

[36] Z. Chen, M. Tomita, S. Doki and S. Okuma, "An extended electromotive force model for sensorless control of interior permanent-magnet synchronous motors," IEEE Trans. Ind. Electron., vol. 50, no. 2, pp. 288-295, Apr. 2003.

[37] Katsuhiko Ogata, "Pole Placement and Observer Design", in Discrete-time Control Systems, 2th ed. China Machine Press, 2004, pp. 456-457.

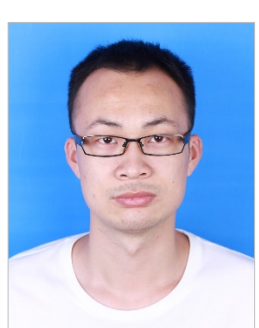

Qingwei Yuan He received the B.Sc. degree from Hunan University, Changsha, China, in 2010. He is currently working toward the Ph.D. degree at Zhejiang University, Hangzhou, China. His current research interests include the direct torque control of interior permanent-magnet synchronous motors and direct-drive wind energy conversion systems.

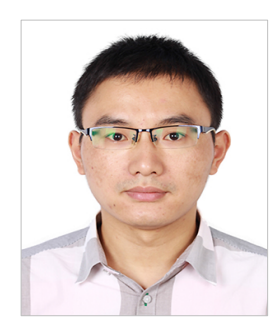

Zhiyong Zeng He received the B.Sc. and M.Sc. degrees in electrical engineering from Anhui University of Science and Technology, Huainan, China, in 2006 and 2009, respectively. $\mathrm{He}$ is currently working toward the Ph.D. degree at Zhejiang University, Hangzhou, China. His current research interests are focused on modeling, modulation, and control of grid connected power converters and fault-tolerant power converters implemented in renewable energy and distributed generation systems. 
Rongxiang Zhao $\mathrm{He}$ received the B.Sc., M.Sc., and Ph.D. degrees in electrical engineering from Zhejiang University, Hangzhou, China, in 1984, 1987 and 1991, respectively. He became a Faculty Member with Zhejiang University in 1991 and was promoted to Associate Professor in December 1994. Since 1997, he has been a Full Professor with the College of Electrical Engineering, Zhejiang University, where he was the Vice Dean of the College of Electrical Engineering. He is currently the Director of the National Engineering Research Center for Applied Power Electronics of China, where he focuses on the integration of enterprises, universities, and research institutes in power electronics applications, such as induction heating, electric vehicle drives, and microgrids. He has published more than 60 technical papers and holds 16 patents. His current research interests include renewable energy generation, motor control, energy storage, and its applications. Dr. Zhao has received six Scientific and Technological Achievement Awards from the Zhejiang Provincial Government and one Science and Technology Progress Award from the State Educational Ministry of China. 